\title{
Emotion causes targeted forgetting of established memories
}

\section{Bryan A. Strange ${ }^{1,2 *}$, Marijn C. W. Kroes ${ }^{1}$, Judith E. Fan ${ }^{1}$ and Raymond J. Dolan ${ }^{1}$}

\author{
1 Wellcome Trust Centre for Neuroimaging, Institute of Neurology, London, UK \\ 2 Centre for Biomedical Technology, Technical University of Madrid, Spain
}

\section{Edited by:}

Yadin Dudai, The Weizmann Institute of

Science, Israel

\section{Reviewed by:}

Serge Laroche, CNRS and University

Paris-Sud, France

Avi Mendelsohn, Weizmann Institute of

Science, Israel

*Correspondence:

Bryan A. Strange, Wellcome Trust Centre for Neuroimaging, 12 Queen

Square, London WC1N 3BG, UK.

e-mail: bstrange@fil.ion.ucl.ac.uk
Reconsolidation postulates that reactivation of a memory trace renders it susceptible to disruption by treatments similar to those that impair initial memory consolidation. Despite evidence that implicit, or non-declarative, human memories can be disrupted at retrieval, a convincing demonstration of selective impairment in retrieval of target episodic memories following reactivation is lacking. In human subjects, we demonstrate that if reactivation of a verbal memory, through successful retrieval, is immediately followed by an emotionally aversive stimulus, a significant impairment is evident in its later recall. This effect is time-dependent and persists for at least 6 days. Thus, in line with a reconsolidation hypothesis, established human episodic memories can be selectively impaired following their retrieval.

Keywords: episodic memory, reconsolidation, consolidation, emotion, retrograde amnesia, cued recall

\section{INTRODUCTION}

Following memory acquisition, there is a period during which memory traces undergo consolidation into long-term memory, a process involving synaptic protein synthesis and changes in gene expression (McGaugh, 2000). Until recently, a prevailing view was that once memory is consolidated, it is immune to manipulations that, prior to consolidation, impair its subsequent retrieval (Squire, 1992; McGaugh, 2000). However, an early study (Misanin et al., 1968) cast doubt on this account by demonstrating that electroconvulsive shock (ECS), known to impair consolidation (Duncan, 1949), impairs expression of a previously consolidated memory if applied immediately after retrieval of that memory. This finding has been replicated and extended in animal models, leading to an hypothesis that retrieved memories must be reconsolidated in order to persist (Przybyslawski and Sara, 1997; Nader et al., 2000a; Nader, 2003).

Convincing support for this phenomenon in humans is limited, primarily because amnesic agents such as protein-synthesis inhibitors and ECS cannot be applied to healthy human subjects as experimental treatments (Rubin et al., 1969). The existing studies supporting modulation of human memory following reactivation demonstrate impaired non-declarative forms of memory, namely fear conditioning (Schiller et al., 2010), fear potentiated startle (Kindt et al., 2009), or motor sequence learning (Walker et al., 2003). By contrast, reconsolidation impairment for specific declarative memories, in particular long-term memories for episodes that are accessible to conscious recollection (i.e., episodic memory), has not been demonstrated. Reconsolidation effects for human episodic memory are limited to decreased memory for a word list implied by a surrogate index of memory (Forcato et al., 2007), or the integration of new list items into a previously learnt list following a reminder (Hupbach et al., 2007). Thus, these studies do not show selective impairment of a specific target episodic memory.

Recently, we described an emotion-induced retrograde amnesia (Strange et al., 2003), a manipulation that provides a potential technique for studying reconsolidation of specific human episodic memories. In brief, stimuli that precede an emotional event during encoding suffer a relative amnesia in subsequent free or cued recall (Strange et al., 2003; Miu et al., 2005). That is, whereas emotional (E) items show a well-described episodic memory enhancement (Cahill and McGaugh, 1998), the preceding (E - 1) items show a relative amnesia. Consequently, this manipulation (an emotional event) shares with interventions like ECS (Duncan, 1949) and protein-synthesis inhibition (Flexner et al., 1963) a fundamental ability to evoke retrograde disruption of memory.

Here, we modified the paradigm associated with emotion-induced retrograde memory disruption at encoding to demonstrate effects consistent with a reconsolidation interpretation. In two pilot studies, Experiments (Exp) 1 and 2, we established that the manipulation used in our reconsolidation experiments (Exp 3-5) could evoke emotion-induced retrograde disruption of verbal memory, as indexed by cued recall. In our previous studies, we employed aversive words as emotional stimuli. However, emotioninduced memory disruption is critically dependent on the amygdala (Strange et al., 2003) and the human amygdala shows strongest responses to affective facial expressions (Sergerie et al., 2008). On this basis, we elected to present fearful faces as the emotional stimuli in the current series of experiments. The critical finding from Exp 1 and 2 is that retrograde amnesia is evident $24 \mathrm{~h}$ after encoding, but not if recall is cued immediately after the study phase, indicating an effect on consolidation. Given the overlap in treatments that disrupt consolidation and reconsolidation (Alberini, 2005), this paradigm provides a framework for selective impairment of a target episodic memory.

The proposal that retrieved memories become labile and must undergo reconsolidation, as expressed in the reconsolidation hypothesis, is highly controversial. Several studies have not replicated a post-retrieval memory impairment effect, while others have suggested alternative explanations for findings labeled as reconsolidation, particularly following observations of complete memory recovery within days (Dudai, 2004; Dudai and Eisenberg, 2004; Eichenbaum, 2006). Animal experiments have led to specific criteria in order for memory disruption to be referred to as a reconsolidation impairment (Nader et al., 2000b). Memory must be disrupted 
following reactivation, as indexed in a subsequent memory test (Przybyslawski and Sara, 1997). The impairment should not be attributable to retrieval failure or a reactivation-locked, temporary inability to access memory traces that dissipates over time (Lattal and Abel, 2004). Impairment should, however, be timedependent and not expressed in tests of immediate memory (Nader et al., 2000a). Finally, the memory impairment must not be due to impaired novel encoding of any attribute of reactivated memories (Nadel and Land, 2000). We satisfy these criteria for disruption of reconsolidation within a series of human experiments (Exp 3-5) where we demonstrate emotion-induced disruption of memory following successful reactivation.

\section{MATERIALS AND METHODS SUBJECTS}

A total of 89 native English-speaking subjects completed Exp 1-5. All subjects gave informed consent and were free of neurological or psychiatric history. The study had full ethics approval. Twenty (10 males, 10 females, age range: $19-37$, mean: 25.6$)$ and 14 (7 males, 7 females, age range: 20-31, mean: 25.6) subjects completed Exp 1 and 2, respectively. Twenty, 15, and 20 subjects completed Exp 3, 4 , and 5, respectively. We have previously shown that in subjects not familiar with the neutral nouns presented in these studies, the chance of correctly completing an item in the employed stimulus set is approximately 11\% (Kroes et al., 2010). On this basis, a performance criterion was set for our reconsolidation studies of recall hit rate minus false alarm rate greater than $10 \%$ for control nouns on Day 2. Thus, data from 16 subjects ( 8 males, 8 females, age range: $21-35$, mean: 27.2$)$ were included in $\operatorname{Exp} 3,11$ subjects (5 males, 6 females, age range: 22-30, mean: 25.6) in Exp 4 and 14 subjects ( 5 males, 1 left-handed, 9 females, age range: $20-28$, mean: 22.6) in $\operatorname{Exp} 5$.

\section{STIMULI}

Verbal stimuli comprised a set of 400 nouns which were "stemunique" in that the first three letters were different for each of the nouns. Faces were selected from the Karolinska Directed Emotional Faces set (Lundqvist et al., 1998), converted to gray scale and framed to exclude non-facial features. An equal number of female and male faces were presented in each experiment.

\section{TASK}

\section{Experiment 1}

Encoding and cued recall sessions were conducted in the same environment, $24 \mathrm{~h}$ apart. On Day 1, subjects viewed 240 nouns, taken from the set of 400 , and made a push-button response to indicate whether the noun described a living or non-living entity. A face was presented after a random number of words (between 3 and 5 ; mean $=4$ ) upon which subjects were instructed to press a third button. Nouns and faces were each presented for $1 \mathrm{~s}$, with a stimulus onset asynchrony (SOA) of $4 \mathrm{~s}$. A total of 60 faces were presented, 30 neutral $(\mathrm{N})$ and 30 fearful (E). Nouns were conditionalized according to their position relative to face presentation and labeled emotional (E) or neutral $(\mathrm{N}) \pm 1$, i.e., a noun that immediately preceded an emotional face is referred to as $\mathrm{E}-1$. Nouns without positional assignment served as controls (C), with the constraint that these controls were more than two nouns before, and more then one noun after, a given face (Figure 1A). On Day 2, word stems were presented every $4 \mathrm{~s}$ (stimulus duration, $1 \mathrm{~s}$ ) and subjects instructed to complete the stems to make a word from Day 1. In all experiments, nouns and word stems were presented in uppercase in random order.

\section{Experiment 2}

This was identical to Exp 1, except that the encoding session was followed immediately by the cued recall task.

\section{Experiment 3}

This experiment was conducted in the same environment, at the same time of day, across four separate days. On Day 1, subjects viewed 400 nouns at a rate of one every $4 \mathrm{~s}$ (stimulus duration, $1 \mathrm{~s}$ ), and made a push-button response to indicate whether the noun described a living or non-living entity. To promote retrieval success across the ensuing cued recall tests, the encoding task was repeated a total of three times. On Day 2 , word stems were presented (stimulus duration $1 \mathrm{~s}$, SOA $4 \mathrm{~s}$ ) and subjects instructed to complete the stems out loud to make a word from Day 1, while avoiding guessing. A face was presented after a random number of word stems (between 3 and 5 ; mean $=4$ ) upon which subjects were instructed to make a button press. A total of 80 faces were presented, 40 neutral (N) and 40 fearful (E). Day 3 and Week 2 (test day 1 week after Day 1) followed the same procedure as Day 2 except that no faces were presented (Figure 2A).

Word stems were conditionalized according to their position relative to face presentation on Day 2 and labeled emotional (E) or neutral $(\mathrm{N}) \pm 1$, i.e., a stem that immediately preceded an emotional face is referred to as $\mathrm{E}-1$. We also examined memory for $\mathrm{E}-2$ and $\mathrm{N}-2$ stems. Word stems without positional assignment served as controls (C), with the constraint that these controls were more than 2 word stems before, and more then 1 word stem after, a given face. Performance on Day 3 and Week 2 is expressed as the proportion of remembered Day 3/Week 2 words that were remembered on Day 2.

\section{Experiment 4}

This was identical to Exp 3 except that the experiment was conducted over 3 days, with Day 2 consisting of 2 cued recall sessions (Test 1 and Test 2) with Test 3 on Day 3 (Figure 2B).

\section{Experiment 5}

This was identical to Exp 3 except that only 100 nouns, taken from the set of 400, were presented on Day 1. Furthermore, on Day 2 only 20 faces were presented, 10 neutral and 10 emotional, with each face presented above a neutral or emotional noun, respectively (Figure 6A). The neutral nouns presented with neutral faces were taken from the stimulus set of 400 nouns. The emotionally aversive nouns presented together with fearful faces were selected from a set used in our previous studies (Strange and Dolan, 2004). The first three letters of these emotional nouns were different from the 100 nouns presented on Day 1. Given the lower number of critical items $(\mathrm{E}-1, \mathrm{~N}-1)$ in this experiment (only 10 emotional and neutral faces were presented on Day 2), we applied a further performance criteria for Exp 3. In view of the conditionality of 
Day 3 performance on Day 2, if only one $\mathrm{E}-1$ or $\mathrm{N}-1$ stem was recalled on Day 2 (i.e., 10\% hit rate) the corresponding conditional performance on Day 3 was excluded from our analyses. Thus 1 subject's hit rate for $\mathrm{E}-1$ stems, and two further subjects for $\mathrm{N}-1$ stems, were excluded ( $\mathrm{E}-1$ effects remained significant if this $\mathrm{E}-1$ hit rate was included).

\section{STATISTICAL ANALYSES}

In view of our strong a priori prediction that cued recall of $\mathrm{E}-1$ nouns would differ relative to control and $\mathrm{N}-1$ nouns, statistical analyses were constrained to planned comparisons. Thus, for all experiments we report separate paired $t$-tests comparing $\mathrm{E}-1$ vs. control and $\mathrm{N}-1$ cued recall. One-tailed significance is reported on the basis of the prediction that memory for $\mathrm{E}-1$ nouns would be impaired. To test for persistence of reconsolidation effects over 1 week (Exp 3 and 5) we report separate word type $\times$ day (Day 3 , Week 2) $2 \times 2$ ANOVAs for $\mathrm{E}-1$ vs. control and $\mathrm{N}-1$ nouns. For Exp 3-5 we did not predict any effect of face presentation on the first test of cued recall (Day 2). To demonstrate that this was indeed the case, we report, for Exp 3-5, emotion $(E, N) \times$ position $(-2,-1,+1) 2 \times 3$ repeated measures ANOVAs for $\%$ Hits relative to controls on Day 2. Although our predictions pertain to $\mathrm{E}-1$ cued recall, we include memory performance for $\mathrm{E}-2, \mathrm{~N}-2$, $\mathrm{E}+1$, and $\mathrm{N}+1$ nouns in our plots of reconsolidation effects for descriptive purposes.

\section{RESULTS EMOTION-INDUCED RETROGRADE DISRUPTION OF CONSOLIDATION}

In our previous studies of emotion-induced retrograde memory impairment at encoding (Strange et al., 2003), 14-word lists were presented with a SOA of $3 \mathrm{~s}$, the emotional (E) stimulus was an emotionally aversive noun and memory was assessed using free recall after a $30 \mathrm{~s}$ filled delay which followed each list. The nature of the reconsolidation task (Exp 3-5) required a longer SOA because presentation of the E stimulus occurred during cued recall, instead of verbal encoding. Thus, we employed an SOA of $4 \mathrm{~s}$ in the recall task to allow completion of cued recall before presentation of the E stimulus (a fearful face). Because of the differences between this and our previous paradigm (Strange et al., 2003), we conducted a pilot study (Exp 1) to first establish that fearful faces, presented $4 \mathrm{~s}$ after the verbal stimulus, evoke emotion-induced retrograde amnesia of verbal encoding, as indexed by cued recall. Given that our main reconsolidation experiments were to be conducted on successive days, the interval between encoding and cued recall in this pilot study was $24 \mathrm{~h}$.

On Day 1, healthy human subjects performed a semantic encoding task on visually presented "stem-unique" nouns. The critical manipulation was that some of these nouns were followed by the visual presentation of a face. Faces could be either emotional (fearful) or neutral. Neutral (N) faces controlled for non-specific effects of face presentation during encoding. On Day 2 , word stems, the first three letters of previously encoded words, were presented and subjects instructed to complete the stems out loud to make a word from Day 1 (Figure 1A). Figure 1B demonstrates a significant emotion-induced retrograde amnesia (i.e., E - 1 effect) when cued recall is tested after a 24 -h delay. Planned comparisons demonstrate a relative decrement of cued recall for $\mathrm{E}-1$ cues (relative to control cues paired $t$-test $t(19)=-3.181 ; p=0.003$ one-tailed; relative to $\mathrm{N}-1$ cues paired $t$-test $t(19)=-2.582 ; p=0.009$ one-tailed). Mean control noun recall was $23.3 \%$ (SEM 1.5).

Successful demonstrations of memory reconsolidation (Nader et al., 2000a; Dudai and Eisenberg, 2004; Tronson et al., 2006) use learning paradigms in which both consolidation and reconsolidation processes could be conclusively affected. To test whether emotion-induced amnesia induced at encoding with the experimental parameters used in Exp 1 reflects an effect consistent with impaired consolidation, we conducted a further pilot experiment. Consolidation impairment is time-dependent, and not expressed in tests of immediate memory retrieval (McGaugh, 2000). Thus, Exp 2 was identical to Exp 1 except that cued recall was tested immediately after encoding. Figure 1C demonstrates that E - 1 memory disruption is not present in immediate tests of cued recall. Planned comparisons confirm no significant effect of cued recall for $\mathrm{E}-1$ cues relative to control cues (paired $t$-test $t(13)=0.545$; $p=0.298$ one-tailed) or relative to $\mathrm{N}-1$ nouns (paired $t$-test $t(13)=0.000 ; p=0.500$ one-tailed). Mean control noun recall was $28.5 \%$ (SEM 2.1).

Thus, E - 1 effects when tested by cued recall were only observed following a 24-h delay, and not on a test of immediate memory, an observation consistent with an emotion-induced retrograde disruption of consolidation. This finding is in contrast to our previously reported emotion-induced amnesia observed under free recall following a 30-s delay (Strange et al., 2003). This indicates that the emotional stimulus, in addition to disrupting consolidation, evokes an immediate interference with an additional process required for successful free recall. It is noteworthy in this context that in our original study (Strange et al., 2003), nouns were presented in semantically related lists, suggesting that the immediate effects at free recall may reflect an emotioninduced disruption of a category-cued retrieval strategy for the E -1 noun.

\section{MEMORY DISRUPTION FOLLOWING REACTIVATION}

Figure 2A illustrates the experimental protocol for Exp 3. On Day 1 , healthy human subjects performed a semantic encoding task on visually presented verbal stimuli. On Day 2, subjects returned to perform a cued recall task. They were presented with stems of previously encoded nouns and instructed to complete the stems out loud. The critical manipulation was that some of these stems were followed by the visual presentation of either an emotional (fearful) or neutral face. Our working hypothesis was that emotional (E) faces would disrupt reconsolidation of the preceding retrieved word ( $\mathrm{E}-1$ words), indexed in a selective retrieval impairment on subsequent tests of cued recall. Neutral $(\mathrm{N})$ faces controlled for non-specific effects of face presentation during the cued recall task. In view of the novel approach to studying reconsolidation in this paradigm, and unknown temporal profile of any potential effect, we also include cued recall performance for $\mathrm{E}-2$ and $\mathrm{N}-2$ word stems in the plots we present.

We did not expect an effect of face presentation on cued recall on Day 2, and Figure 3A demonstrates that this prediction was confirmed. A word type $(\mathrm{E}, \mathrm{N}) \times$ position $(-2,-1,+1) 2 \times 3$ repeated measures ANOVA (for \% Hits relative to controls) 


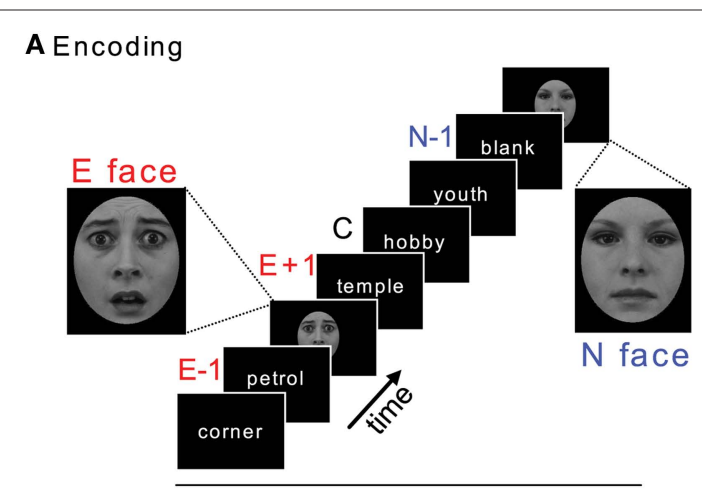

Cued Recall

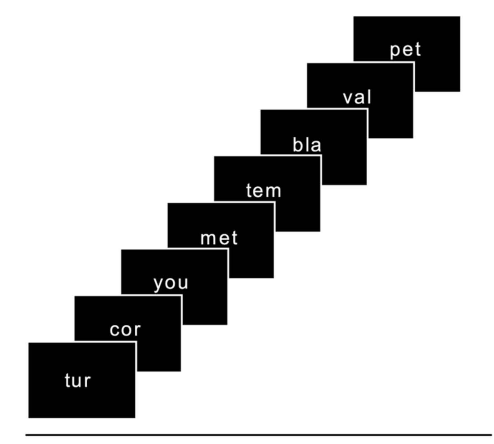

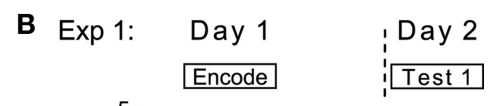

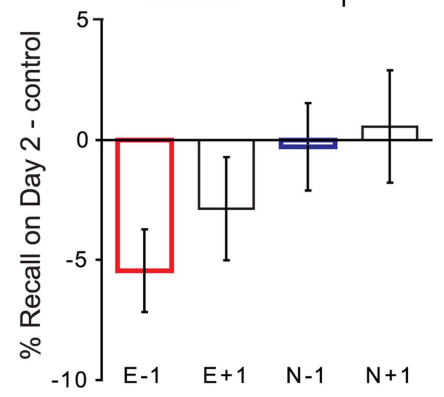

C

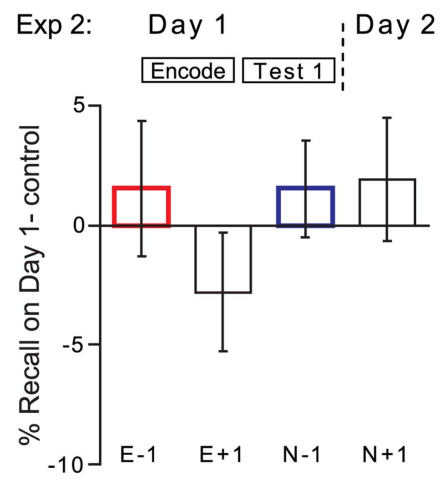

FIGURE 1 | Emotion-induced retrograde disruption of consolidation (Exp 1 and 2). (A) Design of Exp 1 and 2. E, emotional face; N, neutral face; -1, +1, position of word relative to face. (B) Cued recall on Day 2 (\% Hits) minus control for Exp 1. (C) Cued recall on Day 1 for Exp 2 . Error bars, here and in subsequent figures, indicate SEM.

revealed no significant main effect or interaction. The small decrement for $\mathrm{E}-1$ relative to control is non-significant (paired $t$-test $t(15)=-1.297 ; p=0.214$ two-tailed), ensuring equal memory performance for the different word types immediately prior to the reconsolidation disrupting manipulation. To test whether emotional face presentation on Day 2 disrupted the memory trace of E-1 words, we repeated the cued recall task on Day 3. The memory task was identical to Day 2 except that faces were not presented.

Consistent with a reconsolidation hypothesis, a significant percentage of target nouns, i.e., those that preceded emotional faces ( $E-1$ nouns), that were correctly recalled on Day 2 were no longer recalled on Day 3. Thus, on Day 3 there is a selective impairment of cued recall for $\mathrm{E}-1$ cues, relative to control noun cues (Figures 3B,C). Critically, this deficit is not observed for $\mathrm{N}-1$ nouns, i.e., cues that on Day 2 were followed by a neutral face, indicating that it is the fearful emotional facial expression, and not the presentation of a face per se, that leads to impaired $\mathrm{E}-1$ reconsolidation. Planned comparisons confirm the predicted relative decrement of cued recall for $\mathrm{E}-1$ cues (relative to control cues paired $t$-test $t(15)=-2.157 ; p=0.024$ one-tailed; relative to $\mathrm{N}-1$ cues paired $t$-test $t(15)=-1.880$; $p=0.040$ one-tailed). Thus, recall probability of an item previously correctly recalled can be specifically attenuated if, during memory re-activation, it is immediately followed by an emotional stimulus.

\section{VERIDICAL MEMORY RETRIEVAL IS REQUIRED FOR EMOTION-INDUCED SUBSEOUENT MEMORY IMPAIRMENT}

To investigate the specificity of reconsolidation, we next tested whether a retrieval attempt alone immediately prior to an emotional stimulus is sufficient to produce impairment in subsequent memory testing. A small subset of words forgotten on first testing (Day 2) show spontaneous cued recall on second testing (Day 3). If a mere retrieval attempt on Day 2 for $\mathrm{E}-1$ cues leads to impaired reconsolidation then it follows that recall of these words should be impaired on Day 3. Miss rates on Day 2 for E -1 and control cues were both $57.0 \%$ (SE 4.2 and 4.0, respectively). The proportion of these Day 2 misses that were correctly recalled on Day 3 was (mean, SEM) $10.1 \%$ (1.9) and 8.5\% (1.4) for E - 1 and control nouns, respectively. A paired $t$-test confirmed no significant difference $(t(15)=0.864 ; p=0.40$ two-tailed). Thus, veridical memory reactivation, and not retrieval attempt, is required for emotioninduced retrograde impairment of reconsolidation.

\section{POST-REACTIVATION MEMORY IMPAIRMENT PERSISTS OVER TIME}

Animal studies report inconsistent findings as to the durability of reconsolidation impairment with some reporting sustained reconsolidation impairment while others demonstrate spontaneous recovery or reinstatement (Lattal and Abel, 2004; Salinska et al., 2004). In terms of the neurobiology of reconsolidation, reversibility favors a retrieval or performance interpretation, whereas lack of reversal would support a storage deficit (Nadel and Land, 2000; 

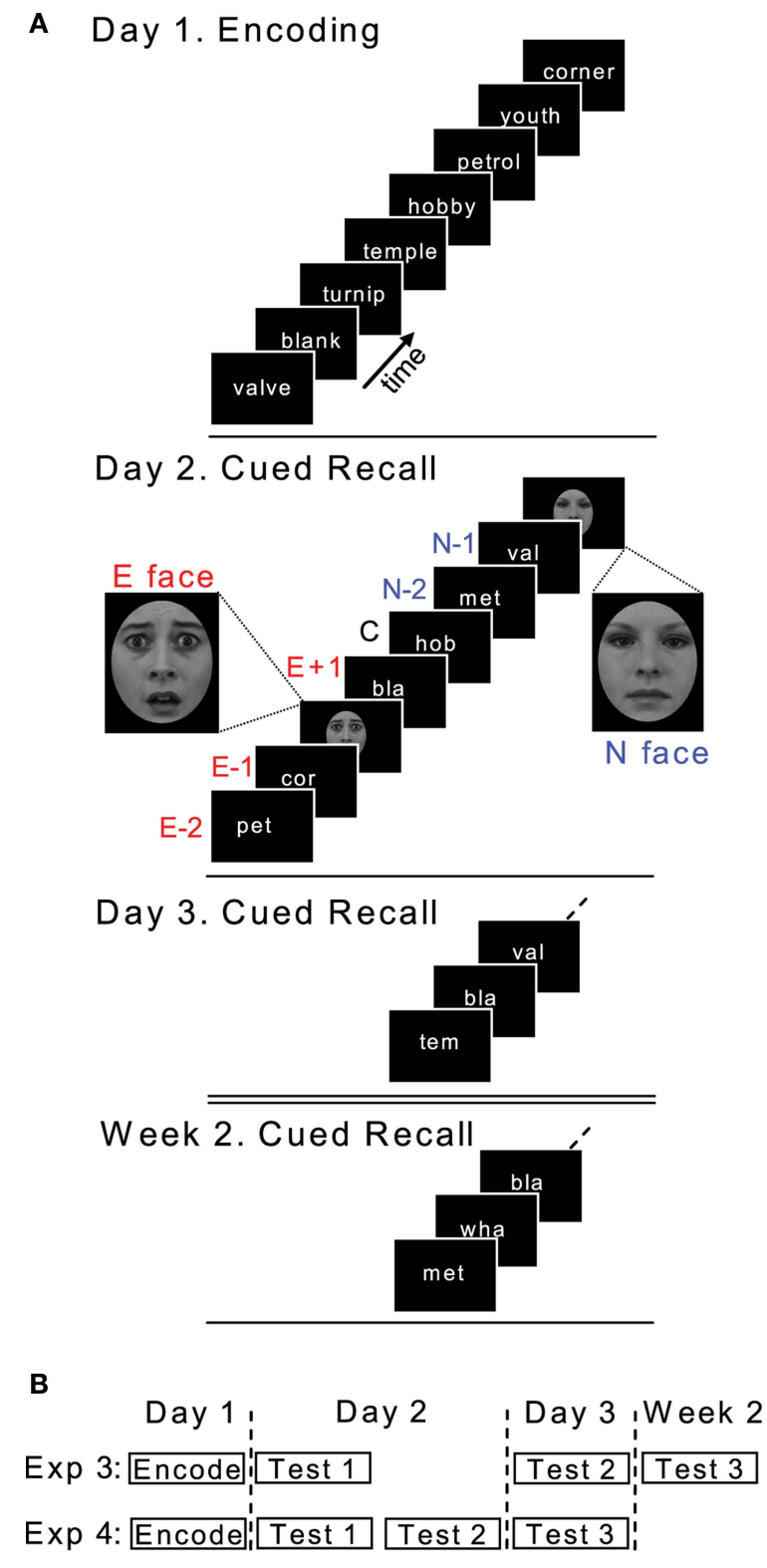

FIGURE 2 | Reconsolidation experimental design. (A) Design of Exp 3. E, emotional face; $N$, neutral face; $-2,-1,+1$, position of word stem relative to face. (B) Time-line of Exp 3 and 4.

Sara, 2000; Dudai and Eisenberg, 2004). We therefore repeated the test of cued recall one week after the initial encoding session (Week 2). Consistent with this effect reflecting a persistent longlasting deficit in reconsolidation, target words, whose cues were followed by an emotional face on Day 2, show impaired recall at Week 2 (Figure 4). A word type $(\mathrm{E}-1$, Control) $\times$ day (Day 3, Week 2) ANOVA for $\%$ Hits demonstrates a significant effect of day $F_{1,14}=7.848, p=0.014$, an effect of word type at trend $F_{1,14}=3.983$, $p=0.066$, and, critically, no word type $\times$ day interaction. Similarly, a word type $(\mathrm{E}-1, \mathrm{~N}-1) \times$ day (Day 3, Week 2) ANOVA for \% Hits relative to control noun recall demonstrates an effect of word type at trend $F_{1,14}=3.396, p=0.087$, and no word type $x$ day interaction.
Thus, the effect we observe endures for at least 6 days and does not represent transient memory impairment for $\mathrm{E}-1$ stimuli, arguing against a retrieval or performance deficit.

\section{MEMORY IMPAIRMENT FOLLOWING REACTIVATION IS TIME- DEPENDENT}

As stated above, for post-reactivation memory disruption to be judged as reconsolidation, the effect must not be due to impaired novel encoding of reactivated memories (Nadel and Land, 2000). Thus, it might be argued that the observed impairment simply reflects recalled E - 1 words not benefiting from a second "encoding" when retrieved on Day 2. Indeed, a counter argument to the reconsolidation hypothesis states that the reactivation of memory causes a second distinct memory trace to be formed (Nadel and Land, 2000; Moscovitch et al., 2005). To control for this possibility we conducted a further experiment (Exp 4), identical in design to our previous experiment, except that on Day 2 subjects performed a second cued recall session immediately after the first, i.e., the initial cued recall session (Test 1) on Day 2, during which emotional and neutral faces were presented, was immediately followed by the cued recall session (Test 2) that, in Exp 3, occurred on Day 3 (Figure 2B). Cued recall on Test 1 was, as in Exp 3, not affected by face presentation. A word type $(\mathrm{E}, \mathrm{N}) \times$ position $(-2,-1,+1) 2 \times 3$ repeated measures ANOVA for $\%$ Hits relative to controls in Test 1 revealed no significant main effect or interaction.

Encoding is defined as the rapid acquisition of a memory trace, a process occurring prior to completion of consolidation (Squire, 1992; McGaugh, 2000). Thus, if the impaired recall of E - 1 stems observed on Day 3 in Exp 3 is simply attributable to lack of secondary encoding, the same effect should be present in the second test (Test 2) of cued recall in Exp 4. Figure 5 demonstrates that this was not the case. There is no decrement for $\mathrm{E}-1$ stems on Test 2 if this comes immediately after Test $1(\mathrm{E}-1$ relative to control noun stems paired $t$-test $t(10)=-0.167 ; p=0.436$ one-tailed; relative to $\mathrm{N}-1$ recall paired $t$-test $t(10)=-0.333 ; p=0.373$ one-tailed). Thus, impaired recall of $\mathrm{E}-1$ words is present $24 \mathrm{~h}$ after the emotional manipulation, supporting a claim that this reflects an emotioninduced impairment of reconsolidation and not a non-specific effect consequent upon impaired re-encoding.

\section{REPLICATION OF INITIAL FINDINGS}

To demonstrate the robustness of $\mathrm{E}-1$ reconsolidation impairment, we conducted a further experiment (Exp 5), identical to Exp 3 except that we now present fearful faces paired with an emotionally aversive noun (Figure 6A). Reliable emotion-induced amnesic effects are evoked by aversive nouns (Strange et al., 2003) and picture-noun pairings (Hurlemann et al., 2005). We also decreased the number of words encoded on Day 1 to increase cued recall performance on Day 2, thereby increasing our sensitivity to memory performance on subsequent testing.

As in Exp 3, there was no significant effect of facial emotional expression or position on Day 2 performance (Figure 6B). An emotion $(\mathrm{E}, \mathrm{N}) \times$ position $(-2,-1,+1) 2 \times 3$ repeated measures ANOVA (for \% Hits relative to controls) on Day 2 revealed no significant main effect or interaction. As shown in Figure 6C, the pattern of emotion-induced reconsolidation impairment on Day 3 is identical to that observed in Exp 1 except that we now observe a 


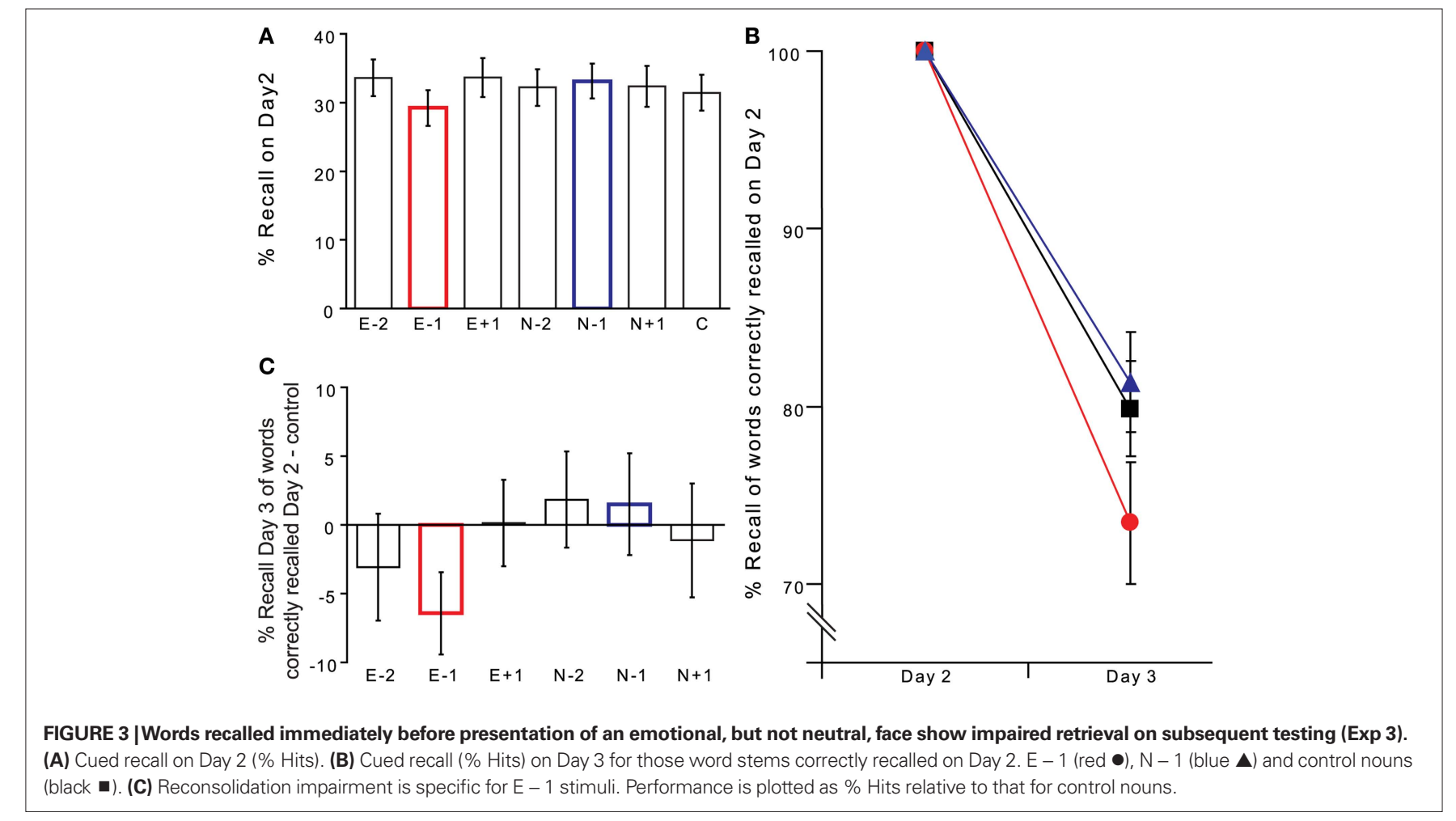

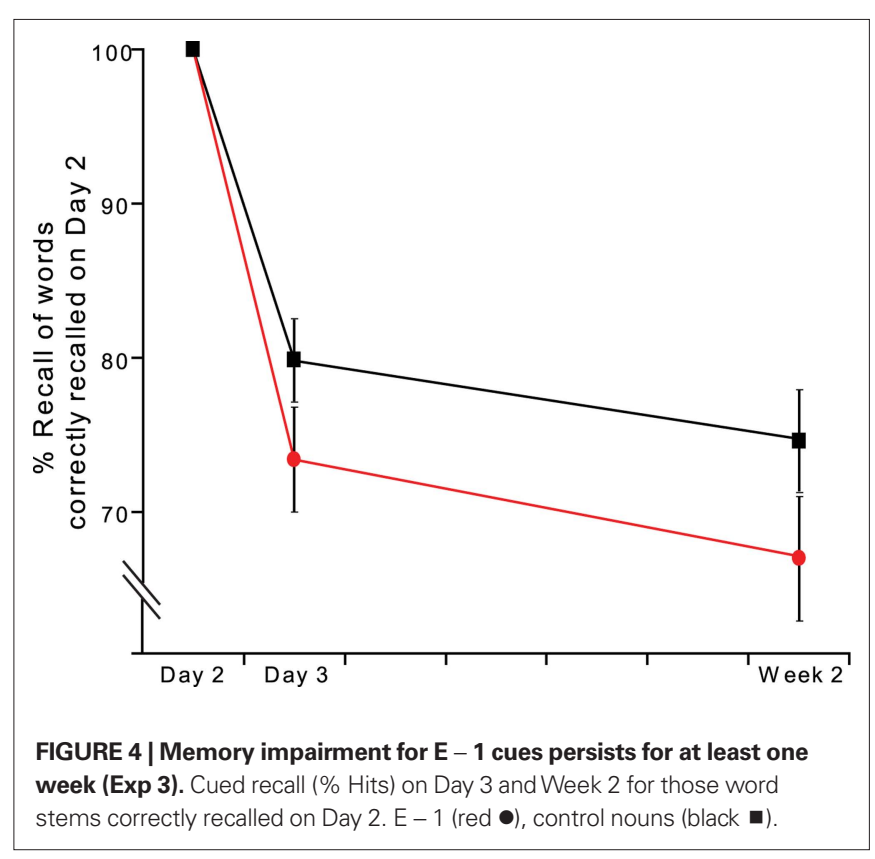

deficit approximately two-times that seen in Exp 1. Planned comparisons confirm the predicted relative decrement of cued recall for $\mathrm{E}-1$ cues (relative to control cues paired $t$-test $t(12)=-2.147$; $p=0.026$ one-tailed).

Figure 6D provides further evidence that the reconsolidation impairment we observe persists over time. A word type (E - 1, Control) $\times$ day (Day 3, Week 2) ANOVA for $\%$ Hits demonstrates a significant effect of word type $F_{1,12}=9.470, p=0.010$, and no

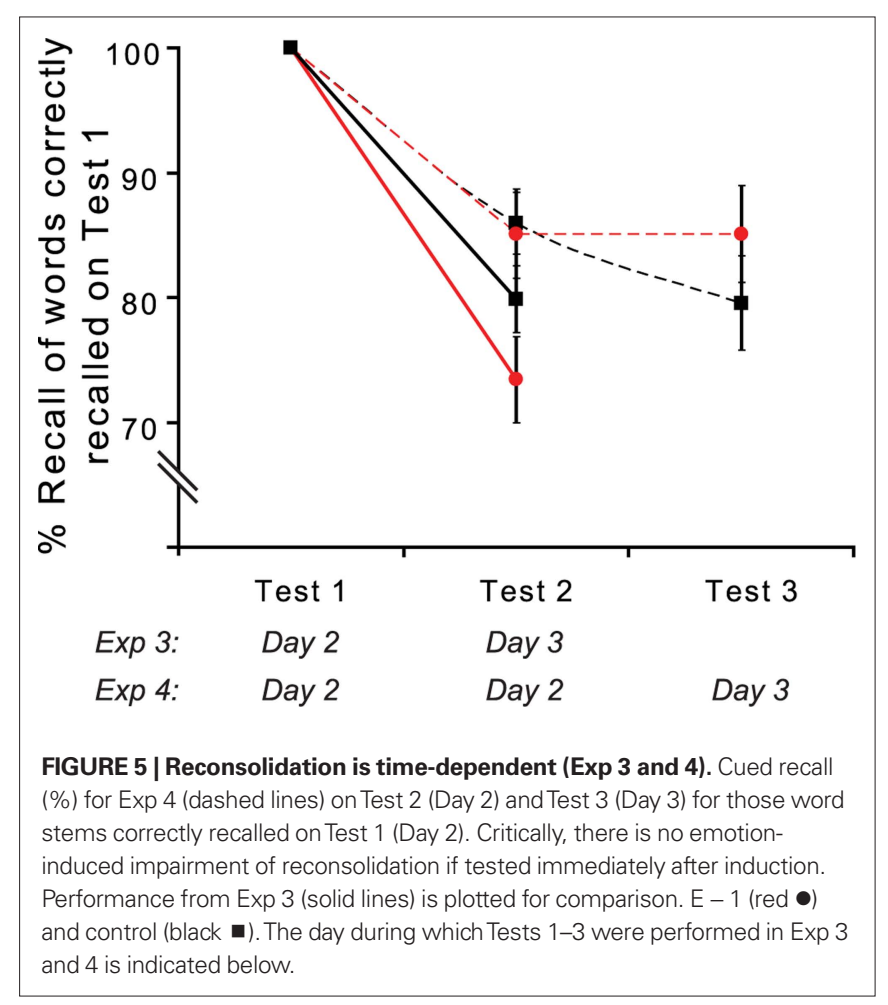

significant main effect of day or word type $\times$ day interaction. A further word type $\times$ day ANOVA comparing $\mathrm{E}-1$ and $\mathrm{N}-1 \%$ Hits also demonstrates a significant effect of word type $F_{1,10}=5.795$, $p=0.037[\mathrm{~N}-1 \%$ Hits (SEM) for those word stems correctly recalled on Day 2 were 93.5 (4.3) for Day 3 and 83.1 (6.7) for 
A

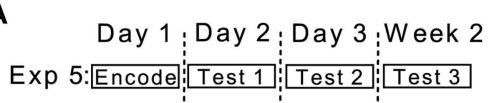

Day 2. Cued Recall

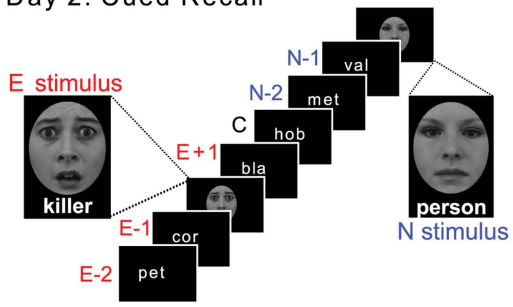

C

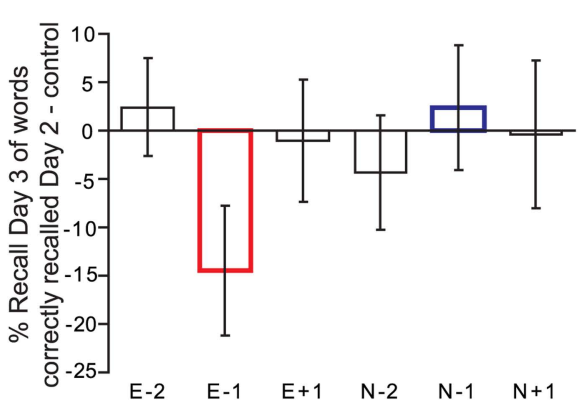

B

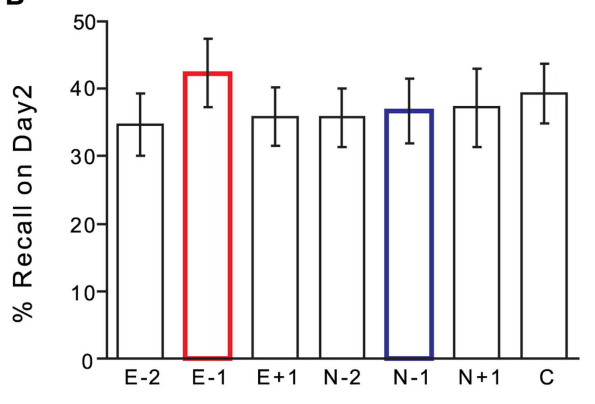

D

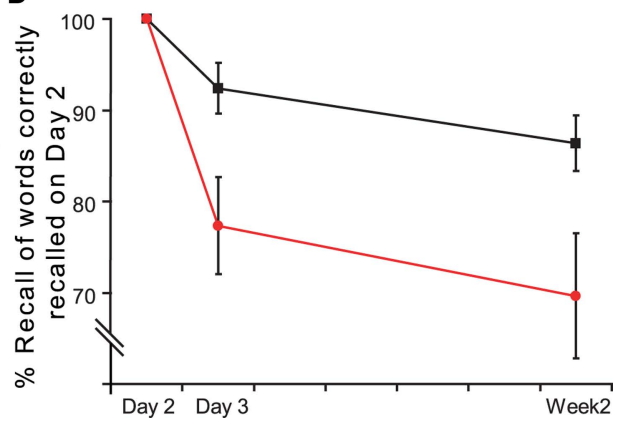

FIGURE 6 | Enhancing reconsolidation impairment (Exp 5). (A) Experimental time-line and design of Exp 5. (B) Cued recall on Day 2 (\% Hits). (C) Reconsolidation impairment is specific for $\mathrm{E}-1$ stimuli. Cued recall on Day 3 for those word stems correctly recalled on Day 2, is plotted as \% Hits relative to that for control nouns. (D) Cued recall (\% Hits) on Day 3 and Week 2 for those word stems correctly recalled on Day 2 plotted as per Figure 4.

Week 2]. Thus, the effect is not attributable to the presentation of a face-word pair per se as neutral pairings did not affect memory on Day 3 or Week 2.

\section{EFFECT SIZE}

Whereas the effect size [Cohen's $d=\left(\right.$ Mean $_{\text {Control }}-$ Mean $\left._{\mathrm{E}-1}\right) /$ pooled standard deviation] for E-1 memory impairment relative to control stems on Day 3 in Exp 3 is equal to 0.52, indicating a moderate effect, the corresponding effect size for Exp 5 is 0.87 , demonstrating that this is a large effect. Corresponding effect sizes relative to $\mathrm{N}-1$ cues are 0.61 and 0.82 for Exp 3 and 5, respectively.

\section{FALSE ALARMS}

The false alarm rates for Exp 3-5 are given in Tables 1-3. Employing the Hit - False alarm rate as the dependent variable in our statistical analyses yielded similar results as described for Hit rate alone. For Exp 3, a word type $(\mathrm{E}-1$, Control) $\times$ day (Day 3, Week 2) ANOVA for \% Hits minus False alarms demonstrates a significant effect of day $F_{1,14}=10.065, p=0.007$, an effect of word type at trend $F_{1,14}=3.655, p=0.077$, and no word type $\times$ day interaction. The same test in Exp 5 reveals a significant effect of word type $F_{1,13}=6.800, p=0.023$.

\section{ANTEROGRADE EFFECTS OF EMOTIONAL STIMULI}

In our original report of impaired $\mathrm{E}-1$ noun free recall (Strange et al., 2003), emotional stimuli were aversive words presented in a neutral word list with a SOA of $3 \mathrm{~s}$. In this previous study (Strange et al., 2003), we observed no difference in recall of $E+1$ nouns
Table 1 | False alarm rates (\%) for Exp 3.

\begin{tabular}{|c|c|c|c|c|c|c|c|}
\hline $\begin{array}{l}\text { Word } \\
\text { type }\end{array}$ & $E-2$ & $E-1$ & $E+1$ & $\mathbf{P}-\mathbf{2}$ & $\mathbf{P}-1$ & $P+1$ & C \\
\hline \multicolumn{8}{|c|}{ DAY 2 FALSE ALARMS } \\
\hline Mean & 13.28 & 13.75 & 14.15 & 11.41 & 11.72 & 10.83 & 11.57 \\
\hline SEM & 2.13 & 2.32 & 3.10 & 2.25 & 2.08 & 2.29 & 1.77 \\
\hline \multicolumn{8}{|c|}{ DAY 3 FALSE ALARMS FOR CORRECTLY RECALLED ON DAY 2} \\
\hline Mean & 5.36 & 3.42 & 1.98 & 3.17 & 4.90 & 5.40 & 3.43 \\
\hline SEM & 2.21 & 1.25 & 0.89 & 1.20 & 1.75 & 1.69 & 1.06 \\
\hline \multicolumn{8}{|c|}{ WEEK 2 FALSE ALARMS FOR CORRECTLY RECALLED ON DAY 2} \\
\hline Mean & 4.70 & 10.10 & 2.30 & 5.27 & 4.23 & 8.09 & 4.02 \\
\hline SEM & 2.02 & 3.42 & 1.38 & 2.06 & 1.74 & 2.53 & 1.45 \\
\hline
\end{tabular}

relative to neutral controls. A further study employing the same experimental paradigm (Miu et al., 2005) also reported no E + 1 memory impairment. However, a similar study, employing a SOA of $5 \mathrm{~s}$, reported significantly impaired recall of stimuli presented immediately after aversive picture-noun pairings (Hurlemann et al., 2005). The current experiments testing for the effects of emotional stimuli at encoding (Exp 1 and 2) employed a SOA of 4 s, i.e., intermediate between the SOAs used in previous studies. It is therefore interesting that recall performance for $\mathrm{E}+1$ cues is numerically less than that for control nouns at both a delayed test (Exp 1, Figure 1B) and immediate test (Exp 2, Figure 1C) of cued recall. Although this apparent cued recall decrement does not reach significance in either Exp $1(\mathrm{E}+1$ relative to control cues paired 
Table 2 | False alarm rates (\%) for Exp 4.

\begin{tabular}{|c|c|c|c|c|c|c|c|}
\hline $\begin{array}{l}\text { Word } \\
\text { Type }\end{array}$ & $\mathrm{E}-2$ & $E-1$ & $E+1$ & $\mathbf{P}-\mathbf{2}$ & $\mathbf{P}-1$ & $P+1$ & C \\
\hline \multicolumn{8}{|c|}{ TEST 1 (DAY 2) FALSE ALARMS } \\
\hline Mean & 5.91 & 7.05 & 9.50 & 5.91 & 7.73 & 9.24 & 6.51 \\
\hline SEM & 1.69 & 2.47 & 2.05 & 1.89 & 2.39 & 2.70 & 1.28 \\
\hline \multicolumn{8}{|c|}{$\begin{array}{l}\text { TEST } 2 \text { (DAY 2) FALSE ALARMS FOR } \\
\text { CORRECTLY RECALLED ONTEST } 1\end{array}$} \\
\hline Mean & 9.51 & 1.82 & 2.67 & 2.21 & 1.01 & 0.91 & 1.57 \\
\hline SEM & 3.54 & 1.22 & 1.76 & 1.51 & 1.01 & 0.91 & 0.86 \\
\hline \multicolumn{8}{|c|}{$\begin{array}{l}\text { TEST } 3 \text { (DAY 3) FALSE ALARMS FOR } \\
\text { CORRECTLY RECALLED ON TEST } 1\end{array}$} \\
\hline Mean & 2.18 & 1.56 & 0.91 & 1.30 & 3.03 & 0.00 & 1.22 \\
\hline SEM & 1.15 & 1.06 & 0.87 & 1.30 & 3.03 & 0.00 & 0.88 \\
\hline
\end{tabular}

Table 3 | False alarm rates (\%) for Exp 5.

\begin{tabular}{llllllll}
\hline $\begin{array}{l}\text { Word } \\
\text { Type }\end{array}$ & $E-2$ & $E-1$ & $E+1$ & $P-2$ & $P-1$ & $P+1$ & $C$
\end{tabular}

\begin{tabular}{|c|c|c|c|c|c|c|c|}
\hline \multicolumn{8}{|c|}{ DAY 2 FALSE ALARMS } \\
\hline Mean & 5.71 & 3.57 & 1.1905 & 2.86 & 9.29 & 8.5289 & 4.02 \\
\hline SEM & 2.28 & 2.25 & 1.1905 & 1.25 & 3.39 & 2.4880 & 1.55 \\
\hline \multicolumn{8}{|c|}{ DAY 3 FALSE ALARMS FOR CORRECTLY RECALLED ON DAY 2} \\
\hline Mean & 0 & 2.45 & 0 & 0 & 0 & 0 & 0.89 \\
\hline SEM. & 0 & 1.69 & 0 & 0 & 0 & 0 & 0.89 \\
\hline \multicolumn{8}{|c|}{ WEEK 2 FALSE ALARMS FOR CORRECTLY RECALLED ON DAY 2} \\
\hline Mean & 4.49 & 3.06 & 3.80 & 0 & 1.02 & 0 & 2.98 \\
\hline SEM & 2.96 & 3.06 & 3.80 & 0 & 1.02 & 0 & 1.60 \\
\hline
\end{tabular}

$t$-test $t(19)=-1.328 ; p=0.200$ two-tailed $)$ or $\operatorname{Exp} 2(\mathrm{E}+1$ relative to control cues paired $t$-test $t(13)=-1.120 ; p=0.283$ two-tailed), this observation suggests that SOAs longer than $3 \mathrm{~s}$ are more likely to lead to $\mathrm{E}+1$ memory impairment if the emotional stimulus is presented at encoding. By contrast, Figures $3 \mathrm{C}$ and $6 \mathrm{C}$ demonstrate that if the emotional stimulus is presented immediately before successful retrieval of $\mathrm{E}+1$ nouns, there is essentially no decrement of $\mathrm{E}+1$ noun recall on subsequent testing (i.e., no reconsolidation impairment for $\mathrm{E}+1$ nouns). This may, therefore, raise a possibility of greater resistance of established memories to anterograde disruption of reconsolidation evoked by an emotional stimulus, relative to anterograde disruption evoked at encoding.

\section{DISCUSSION}

We demonstrate selective impairment in reconsolidation of target episodic memories following successful reactivation. In a series of experiments, we systematically address the criteria generated by animal models for memory disruption to reflect reconsolidation impairment. We show that impaired reconsolidation occurs if an emotionally aversive stimulus is presented immediately after successful reactivation of a memory. Successful memory reactivation is critical, in that retrieval attempt is insufficient to impair subsequent cued recall. This retrograde effect is long-lasting, enduring at least one week, arguing against a retrieval or performance deficit. Critically, the reconsolidation impairment we report is time-dependent in that it is observed after a 24-h delay, but not in immediate tests of cued recall. Our data therefore provide evidence that is consistent with reconsolidation of episodic memory, and its disruption, in humans.

Reconsolidation is postulated to be an adaptive update mechanism by which new information is incorporated into old memories (Lewis, 1979; Alberini, 2005; Eichenbaum, 2006; Morris et al., 2006; Hupbach et al., 2007; Lee et al., 2008; Monfils et al., 2009); but see (Debiec et al., 2006). Indeed, reactivation of an established episodic memory has been shown to modify its content (Hupbach et al., 2007, 2009). We suggest that the reconsolidation effects reported here reflect a process whereby disrupting the integration of retrieved nouns by the presentation of an emotional face corrupts a pre-existent memory trace (Eichenbaum, 2006; Morris et al., 2006). This is not simply disrupted re-encoding of recalled items because the reported reconsolidation impairment is timedependent, being detectable only $24 \mathrm{~h}$ after it is induced, and not immediately following induction.

The exact mechanism by which a fearful face corrupts a preexisting verbal memory remains to be determined. Our previous studies on emotional memory encoding demonstrate that impaired memory for $\mathrm{E}-1$ items is coupled to enhanced memory for the emotional stimuli (Strange et al., 2003). These effects are critically dependent on both amygdala and central adrenergic activation, suggesting that while memory is enhanced if adrenergic activation occurs at the time of encoding, it may be impaired if occurring 3-6 s after the initial encoding event (Strange et al., 2003). If an analogous mechanism mediates the reconsolidation impairment observed in the current studies, this would predict enhanced memory for the fearful faces themselves. We tested this hypothesis in a further experiment (Supplementary Exp 1, see Supplementary material) which followed a similar experimental protocol to Exp 5, with the addition of a surprise recognition memory test on faces presented on Day 2. Consistent with our hypothesis, reconsolidation impairment of E- 1 word stems was associated with enhanced recollection of fearful, but not neutral, faces (see Supplementary Material).

We therefore suggest that the reconsolidation impairment we observe is mediated by an amygdala-dependent adrenergic release, evoked by fearful face presentation, which boosts face memory while corrupting a pre-existent memory trace reactivated sometime in the preceding $4 \mathrm{~s}$. Validation of this proposed mechanism will require a demonstration that pharmacological blockade of the adrenergic system blocks reconsolidation impairment and enhanced memory for fearful faces. It is unlikely that reconsolidation impairment reflects physiological arousal evoked by fearful faces. Emotion-induced memory enhancements do not require peripheral adrenergic engagement (van Stegeren et al., 1998). Furthermore, previous data demonstrate that although fearful faces elicit robust amygdala responses (Hariri et al., 2002; Sergerie et al., 2008), they do not elicit reliable increases in physiological measures of arousal relative to neutral faces (Anderson et al., 2006b). We suggest instead that the impaired reconsolidation effects we observe are likely to be mediated by rapid central adrenergic release within the amygdala.

An interesting additional observation from Exp 4 (Figure 5) is that normal retrieval of $\mathrm{E}-1$ cues during Test 2 immediately after our reconsolidation disrupting manipulation (Test 1), prevents the 
emergence of impaired reconsolidation $24 \mathrm{~h}$ later (Test 3). There are two potential explanations for this finding. Firstly, correct retrieval at Test 2 may re-stabilize the memory trace before emotion-induced retrograde disruption of reconsolidation is complete. Alternatively, performance for $\mathrm{E}-1$ cues on Test 3 might be supported by secondary encoding, the process whereby during every retrieval episode, retrieved mnemonic information, together with incoming sensory information, is stored as a novel memory trace (Nadel and Moscovitch, 1997). This latter explanation suggests that, although reconsolidation of the original verbal memory is disrupted, normal levels of retrieval at Test 3 reflect cued recall of the novel memory trace formed at Test 2 .

A recent study reports a manipulation which completely impairs human fear conditioned memory following reactivation, while leaving declarative memory for the acquired contingency between the conditioned and unconditioned stimulus intact (Kindt et al., 2009). This suggests that declarative memories are more resistant to reconsolidation disruption relative to non-declarative forms. Whereas conditioned fear could reflect a discrete neural representation localized to the amygdala, declarative memories are thought to comprise a distributed cortical representation (Squire, 1992; Kuhl et al., 2010). This distributed representation may explain why our manipulation partially impairs reconsolidation, as opposed to the complete impairment following reactivation observed in human fear conditioning studies (Kindt et al., 2009; Schiller et al., 2010). However, despite the relative resistance of declarative memory to reconsolidation impairment, our manipulation achieves approximately 20\% reduced retrieval probability of a target episodic memory by the second week of testing (Figure 6D). A similar effect magnitude was observed in a recent report (Schwabe and Wolf, 2009) suggesting reconsolidation of recalled autobiographical memory. In this study (Schwabe and Wolf, 2009), new learning of Bartlett's "War of the Ghosts" narrative after the reactivation of a personal, autobiographical neutral experience impaired subsequent memory for that experience. Interestingly, the "War of the Ghosts" narrative has been shown to be mildly emotionally arousing (Adreano and Cahill, 2006), which may, in view of the effects we report, have contributed to the reconsolidation impairment reported by Schwabe and Wolf (2009).

A further factor contributing to the smaller magnitude of reconsolidation impairment described here, relative to that observed in tests of non-declarative memory (Kindt et al., 2009; Schiller et al., 2010), is inter-subject variability. Averaging over subjects we observe significant reconsolidation impairment in both Exp 3 and 5. However, of the 16 subjects included in our analyses of Exp 3, 10 showed reconsolidation impairment (mean 12.9\% decrease relative to control noun recall on Day 3), 1 subject showed no differential E - 1 memory and 5 showed a slight E - 1 memory enhancement. Similarly, of the 14 subjects included in Exp 5, 9

\section{REFERENCES}

Adreano, J. M., and Cahill, L. (2006). Glucocorticoid release and memory consolidation in men and women. Psychol. Sci. 17, 466-470.

Alberini, C. M. (2005). Mechanisms of memory stabilization: are consolidation and reconsolidation similar or distinct processes? Trends Neurosci. 28, 51-56.

Anderson, A. K., Wais, P. E., and Gabrieli, J. D. E. (2006a). Emotion enhances remembrance of neutral events past. PNAS 103, 1599-1604.

showed reconsolidation impairment (mean 27.8\% decrease relative to control noun recall on Day 3 ) whereas 2 subjects showed no differential E- 1 memory and 3 showed E - 1 memory enhancement. This variability mirrors the discrepancies between studies reporting an impairing retrograde effect of emotion on memory encoding (Strange et al., 2003; Hurlemann et al., 2005; Miu et al., 2005) and those demonstrating a retrograde enhancement (Anderson et al., 2006a; Knight and Mather, 2009). With respect to E - 1 effects at encoding, it has been shown that the magnitude of memory impairment depends on subjects' genotype (Strange et al., 2008), level of anxiety trait (Miu et al., 2005), and gender, with females showing greater impairment than males (Strange et al., 2003). Whether these factors also influence emotion-induced retrograde reconsolidation impairment is yet to be determined. Both males and females were included in the current experiments, (and both showed reconsolidation impairment) although sample sizes were insufficient to make inferences on gender effects. As described above, the time interval between neutral and emotional stimuli, i.e., SOA, may influence the magnitude of reconsolidation impairment, which could in turn interact with other variables such as genotype, temperament, and gender. Furthermore, future studies which measure the degree of arousal elicited by specific emotional stimuli, and how this varies between subjects, will also contribute to our understanding of inter-subject variability in $\mathrm{E}-1$ reconsolidation impairment. It is unlikely in the current study that individuals' general memory ability contributed to inter-individual differences in $\mathrm{E}-1$ effects. The correlations between control noun cued recall on first testing (Day 2) and E- 1 memory relative to control nouns on Day 3 were not significant in $\operatorname{Exp} 3$ (Pearson's $r=0.02 ; p=0.930$ ) or Exp 5 (Pearson's $r=-0.02 ; p=0.948$ ).

Reconsolidation is proposed to provide a principled basis for therapeutic interventions in conditions such as post-traumatic stress disorder (PTSD), where the aim is to selectively decrease the strength of aversive memories for traumatic events (Nader et al., 2000b; McCleery and Harvey, 2004; Debiec and Ledoux, 2006; Brunet et al., 2008). Although we address reconsolidation of neutral as opposed to aversive memory, the critical observation here is that reconsolidation of specific human episodic memories can be selectively impaired. Moreover, this can be achieved via a non-invasive psychological manipulation. Future studies might usefully extend these observations to the context of human emotional episodic memory, with testing intervals longer than 1 week necessary to determine the clinical potential of these effects. In conclusion, we demonstrate a targeted, selective reduction in established episodic memory, a finding that provides a potential framework for treatments aimed at reducing unwanted human memories.

\section{ACKNOWLEDGMENTS}

This research was supported by a Wellcome Trust Programme Grant to R.D. We thank M Rugg for assistance with stimuli.

Anderson, A. K., Yamaguchi, Y., Grabski, W., and Lacka, D. (2006b). Emotional memories are not all created equal: evidence for selective memory enhancement. Learn. Mem. 13, 711-718.

Brunet,A., Orr,S.P., Tremblay,J., Robertson, K., Nader, K., and Pitman, R. K. (2008).
Effect of post-retrieval propranolol on psychophysiologic responding during subsequent script-driven traumatic imagery in post-traumatic stress disorder. J. Psychiatr. Res. 42, 503-506.

Cahill, L., and McGaugh, J. L. (1998). Mechanisms of emotional arousal and 
lasting declarative memory. Trends Neurosci. 21, 294-299.

Debiec, J., and Ledoux, J. E. (2006). Noradrenergic signaling in the amygdala contributes to the reconsolidation of fear memory: treatment implications for PTSD. Ann. N.Y.Acad. Sci. 1071, 521-524.

Debiec, J., Doyere, V., Nader, K., and LeDoux, J. E. (2006). Directly reactivated, but not indirectly reactivated, memories undergo reconsolidation in the amygdala. Proc. Natl. Acad. Sci. U.S.A. 103, 3428-3433.

Dudai, Y. (2004). The neurobiology of consolidations, or, how stable is the engram? Annu. Rev. Psychol. 55, 51-86.

Dudai, Y., and Eisenberg, M. (2004). Rites of passage of the engram: reconsolidation and the lingering consolidation hypothesis. Neuron 44, 93-100.

Duncan, C. (1949). The retroactive effect of electroshock on learning. J. Comp. Physiol. Psychol. 42, 32-44.

Eichenbaum, H. (2006). The secret life of memories. Neuron 50, 350-352.

Flexner, J. B., Flexner, L. B., and Stellar, E. (1963). Memory in mice as affected by intracerebral puromycin. Science 141, 57-59.

Forcato, C., Burgos, V. L., Argibay, P. F., Molina, V. A., Pedreira, M. E., and Maldonado,H.(2007).Reconsolidation of declarative memory in humans. Learn. Mem. 14, 295-303.

Hariri, A. R., Tessitore, A., Mattay, V. S., Fera, F., and Weinberger, D. R. (2002). The amygdala response to emotional stimuli: a comparison of faces and scenes. Neuroimage 17, 317-323.

Hupbach, A., Gomez, R., Hardt, O., and Nadel, L. (2007). Reconsolidation of episodic memories: a subtle reminder triggers integration of new information. Learn. Mem. 14, 47-53.

Hupbach, A., Gomez, R., and Nadel, L. (2009). Episodic memory reconsolidation: updating or source confusion? Memory 17, 502-510.

Hurlemann, R., Hawellek, B., Matusch, A., Kolsch, H., Wollersen, H., Madea, B., Vogeley, K., Maier, W., and Dolan, R. J. (2005). Noradrenergic modulation of emotion-induced forgetting and remembering. J. Neurosci. 25, 6343-6349.

Kindt, M., Soeter, M., and Vervliet, B. (2009). Beyond extinction: erasing human fear responses and preventing the return of fear. Nat. Neurosci. $12,256-258$

Knight, M., and Mather, M. (2009). Reconciling findings of emotioninduced memory enhancement and impairment of preceding items. Emotion 9, 763-781.

Kroes, M. C. W., Strange, B. A., and Dolan, R. J. (2010). $\beta$-adrenergic blockade during memory retrieval in humans evokes a sustained reduction of declarative emotional memory enhancement. J. Neurosci. 30 , 3959-3963.

Kuhl, B. A., Shah, A. T., DuBrow, S., and Wagner, A. D. (2010). Resistance to forgetting associated with hippocampus-mediated reactivation during new learning. Nat. Neurosci. 13, 501-506.

Lattal, K. M., and Abel, T. (2004). Behavioral impairments caused by injections of the protein synthesis inhibitor anisomycin after contextual retrieval reverse with time. Proc. Natl. Acad. Sci. U.S.A. 101, 4667-4672.

Lee, S.-H, Choi, J.-H, Lee, N., Lee, H.-R, Kim, J.-I, Yu, N.-K, Choi, S.-L, Lee, S.-H, Kim, H., and Kaang, B.-K. (2008). Synaptic protein degradation underlies destabilization of retrieved fear memory. Science 319, 1253-1256.

Lewis, D. J. (1979). Psychobiology of active and inactive memory. Psychol. Bull. 86, 1054-1083.

Lundqvist, D., Flykt, A., and Öhman, A. (1998). The Karolinska Directed Emotional Faces - KDEF. CD ROM from Department of Clinical Neuroscience, Psychology section, Karolinska Institutet, Stockholm, Sweden.

McCleery, J. M., and Harvey, A. G. (2004). Integration of psychological and biological approaches to trauma memory: implications for pharmacological prevention of PTSD. J. Trauma Stress 17, 485-496.

McGaugh, J. L. (2000). Memory - a century of consolidation. Science 287, 248-251.

Misanin, J.R., Miller, R. R., and Lewis, D. J. (1968). Retrograde amnesia produced by electroconvulsive shock after reactivation of a consolidated memory trace. Science 160, 554-555.

Miu, A., Heilman, R., Opre, A., and Miclea, M. (2005). Emotion-induced retrograde amnesia and trait anxiety. J. Exp. Psychol. Learn Mem. Cogn. 31, 1250-1270.

Monfils, M.-H., Cowansage, K. K., Klann, E., and LeDoux, J. E. (2009). Extinction-reconsolidation boundaries: key to persistent attenuation of fear memories. Science 314, 951-955.

Morris, R. G. M., Inglis, J., Ainge, J. A. Olverman, H. J., Tulloch, J., Dudai, Y., and Kelly, P. A. T. (2006). Memory reconsolidation: sensitivity of spatial memory to inhibition of protein synthesis in dorsal hippocampus during encoding and retrieval. Neuron 50 479-489.

Moscovitch, M., Rosenbaum, R. S., Gilboa, A., Addis, D. R., Westmacott, R., Grady, C., McAndrews, M. P., Levine, B., Black, S., Winocur, G., and Nadel, L. (2005). Functional neuroanatomy of remote episodic, semantic and spatial memory: a unified account based on multiple trace theory. J. Anat. 207, 35-66.

Nadel, L., and Land, C. (2000). Commentary - reconsolidation: memory traces revisited. Nat. Rev Neurosci. 1, 209-212.

Nadel, L., and Moscovitch, M. (1997). Memory consolidation, retrograde amnesia and the hippocampal complex. Curr. Opin. Neurobiol. 7, 217-227.

Nader,K. (2003). Memory tracesunbound. Trends Neurosci. 26, 65-72.

Nader, K., Schafe, G. E., and LeDoux, J. E. (2000a). Fear memories require protein synthesis in the amygdala for reconsolidation after retrieval. Nature 406, 722-726.

Nader, K., Schafe, G. E., and LeDoux, J. E. (2000b). The labile nature of consolidation theory. Nat. Rev. Neurosci. 1,216 .

Przybyslawski, J., and Sara, S. J. (1997) Reconsolidation of memory after its reactivation. Behav. Brain Res. 84 241-246.

Rubin, R., Fried, R., and Franks, C. (1969). "New application of ECT," in Advances in Behavioral Therapy, 1968, ed. Rubin R. Franks (New York: Academic Press), 37-44.

Salinska, E., Bourne, R. C., and Rose, S. P. R. (2004). Reminder effects: the molecular cascade following a reminder in young chicks does not recapitulate that following training on a passive avoidance task. Eur. J. Neurosci. 19, 3042-3047.

Sara, S. J. (2000). Retrieval and reconsolidation: toward a neurobiology of remembering. Learn. Mem. 7 , 73-84.

Schiller, D., Monfils, M.-H., Raio, C. M., Johnson, D. C., LeDoux, J. E., and Phelps, E. A. (2010). Preventing the return of fear in humans using reconsolidation update mechanisms. Nature 463, 49-53.

Schwabe, L., and Wolf, O. T. (2009). New episodic learning interferes with the reconsolidation of autobiographical memories. PLoS One 4, e7519. doi:10.1371/journal.pone.0007519.

Sergerie, K., Chochol, C., and Armony, J. L. (2008). The role of the amygdala in emotional processing: a quantitative meta-analysis of functional neuroimaging studies. Neurosci. Biobehav. Rev. 32, 811-830.

Squire, L. R. (1992). Memory and the hippocampus: a synthesis from findings with rats, monkeys, and humans. Psychol. Rev. 99, 195-231.

Strange, B. A., and Dolan, R. J. (2004). $\beta$-adrenergic modulation of emotional memory-evoked human amygdala and hippocampal responses. Proc. Natl. Acad. Sci. U.S.A. 101, 11454-11458

Strange, B. A., Hurlemann, R., and Dolan, R. J. (2003). An emotion-induced retrograde amnesia in humans is amygdala- and (-adrenergic-dependent. Proc. Natl. Acad. Sci. U.S.A. 100, 13626-13631.

Strange, B. A., Kroes, M. C. W., Roiser, J. P., Tan, G. C. Y., and Dolan, R. J. (2008). Emotion-induced retrograde amnesia is determined by a $5-\mathrm{htt}$ genetic polymorphism. J. Neurosci. 28, 7036-7039.

Tronson, N. C., Wiseman, S. L., Olausson, P., and Taylor, J. R. (2006) Bidirectional behavioral plasticity of memory reconsolidation depends on amygdalar protein kinase a. Nat. Neurosci. 9, 167-169.

van Stegeren, A. H., Everaerd, W., Cahill, L., McGaugh, J. L., and Gooren, L. J. G. (1998). Memory for emotional events: differential effects of centrally versus peripherally acting $\beta$-blocking agents. Psychopharmacology 138, 305-310.

Walker, M. P., Brakefield, T., Allan Hobson, J., and Stickgold, R. (2003). Dissociable stages of human memory consolidation and reconsolidation. Nature 425 , 616-620.

Conflict of Interest Statement: The authors declare that the research was conducted in the absence of any commercial or financial relationships that could be construed as a potential conflict of interest.

Received: 28 May 2010; paper pending published: 13 August 2010; accepted: 27 October 2010; published online: 19 November 2010.

Citation: Strange BA, Kroes MCW, Fan JE and Dolan RJ (2010) Emotion causes targeted forgetting of established memories. Front. Behav. Neurosci. 4:175. doi: 10.3389/ fnbeh.2010.00175

Copyright $(02010$ Strange, Kroes, Fan and Dolan. This is an open-access article subject to an exclusive license agreement between the authors and the Frontiers Research Foundation, which permits unrestricted use, distribution, and reproduction in any medium, provided the original authors and source are credited. 


\section{APPENDIX}

\section{SUPPLEMENTARY EXPERIMENT 1 (EXP S1) EXPERIMENT S1 INTRODUCTION}

Our previous work on emotion-induced retrograde amnesia (Strange et al., 2003) shows that memory impairment for nouns preceding an emotional event is coupled to an enhanced memory for the emotional verbal stimulus itself. Both effects are critically dependent on the amygdala and the adrenergic system, suggesting that adrenergic activation at the time of encoding results in memory enhancement and an impairment if occurring 3-6 s after initial encoding (Strange et al., 2003). In the current series of experiments (Exp 1-5, see main text), the emotional stimuli employed were fearful faces. As stated in the main text, an analogous mechanism mediating the reconsolidation impairment observed in Exp 3 and 5 would predict enhanced memory for the fearful faces themselves. Enhanced memory for fearful vs. neutral faces has been observed in some (Sergerie et al., 2005), but not all studies (Anderson et al., 2006). Thus, Exp S1 was conducted to test for enhanced memory for emotional faces within the context of the current experimental design. Therefore we included, in addition to tests of cued verbal recall, a recognition memory task for face stimuli. Specifically, subjects encoded nouns on Day 1 and on Day 2 performed a cued recall task (Test 1 ) in a manner identical to Exp 5 (see main text). However, the subsequent cued recall task (Test 2) was followed by a recognition memory task for fearful and neutral faces previously presented during Test 1 . We employed a "Remember/Know" (R/K) (Tulving, 1985) recognition memory task on the basis of previous evidence that recollection (" $\mathrm{R}$ " responses) of emotional stimuli, as opposed to familiarity ("K"), drives a memory advantage for emotional stimuli as well as an enhanced amygdala response during emotional memory retrieval (Dolcos et al., 2005).

As an additional manipulation, we included a pharmacological factor in the design of this experiment. We have previously shown that emotion-induced retrograde amnesia at encoding is critically dependent on the adrenergic system, as it is reversed by the $\beta_{1} \beta_{2}$ antagonist Propranolol (Strange et al., 2003). By contrast, augmentation of emotion-induced retrograde amnesia has been reported when noradrenaline levels are increased by administering Reboxetine (a selective noradrenaline reuptake inhibitor) at encoding (Hurlemann et al., 2005). It should be noted, however, that studies on the effects of acute Reboxetine administration on memory for emotional stimuli have generally shown no modulation of recall of negative valence stimuli (Papps et al., 2002; Harmer et al., 2003; Chamberlain et al., 2006). Nevertheless, we tested an hypothesis that administration of Reboxetine, prior to our reconsolidation impairment manipulation, would increase the magnitude of this impairment.

\section{EXPERIMENT S1 METHODS SUBJECTS}

Thirty right-handed, native English-speaking subjects ( 16 males, 14 females) completed this double-blind, placebo-controlled experiment. All subjects gave informed consent, were free of neurological or psychiatric history, and not on any medication. The study had full ethics approval. One subject in the Reboxetine group was excluded due to vomiting post-drug administration. A performance criterion was set of a recall hit minus false alarm rate greater than
$10 \%$ for control nouns on Day 2. Thus, data from 22 subjects [ 11 in the placebo group ( 6 males, 5 females, age range 20-34, mean 26.8 ) and 11 in the Reboxetine group ( 6 males, 5 females, age range 20-26, mean 22.8)] were included in Exp S1.

\section{TASK}

The experimental design was identical to Exp 5 (see main text) except for the following. On Day 1, prior to performing the encoding task, an electrocardiogram was recorded for each subject, and blood pressure (BP) taken. On Day 2, subjects were administered either a $4 \mathrm{mg}$ oral dose of Reboxetine (Edronax, Pharmacia UK) or a $100 \mathrm{mg}$ oral dose of ascorbic acid (placebo pill). In view of the kinetics of Reboxetine's peak plasma concentration $(\sim 2 \mathrm{~h})$, the cued recall task (Test 1 ) commenced 120 min after drug administration (Figure S1A). BP was recorded immediately prior to drug administration (time $0 \mathrm{~h}$ ) and again before commencing the task (time +2 h). In Exp 3-5 (see main text), the second cued recall task (Test 2) was performed on Day 3. Given the half-life of Reboxetine $(\sim 13 \mathrm{~h})$, Test 2 in the current experiment was performed on Day 4 (i.e. $48 \mathrm{~h}$ later) to ensure that several half lives had elapsed, thus minimizing drug effects on Test 2. For each subject, all cued recall testing was conducted in the same environment, and began at the same time of day, as the Encoding session.

Immediately following cued recall Test 2 , subjects performed a surprise memory test on the faces that had been presented during Test 1 . Faces were presented in the absence of the corresponding neutral or emotional noun presented simultaneously in Test 1 . Thus, these 10 neutral and 10 fearful faces were randomly presented along with 10 neutral and 10 fearful foils (stimulus duration $1 \mathrm{~s}$, SOA $4 \mathrm{~s}$ ). Subjects made a key-press response to indicate whether they remembered $(\mathrm{R})$ having seen the face, felt the face was familiar but did not have a sensation of recollection associated with the face $(K)$, or thought the face was new $(N)$, i.e., a foil. Subjects then returned 1 week after the initial encoding session (Week 2) and repeated the cued recall for the third time (Test 3 ).

\section{EXPERIMENT S1 RESULTS AND DISCUSSION}

In addition to replicating the reconsolidation impairment observed in Exp 3 and 5 (see main text), the results of this study demonstrate an enhanced memory for fearful vs. neutral face stimuli presented on Day 2 in Exp 1-5. The selective noradrenaline reuptake inhibitor Reboxetine did not modulate any index of memory performance.

Figure S1B illustrates that cued recall on Day 2 was not significantly affected by face presentation or drug. A group (placebo, Reboxetine) $x$ noun type $(\mathrm{E}, \mathrm{N}) \times$ position $(-2,-1,+1) 2 \times 2 \times 3$ repeated measures ANOVA (for \% Hits relative to controls) revealed no significant main effect or interaction. There was no effect of Reboxetine on control noun cued recall (independent $t$-test $t(20)=1.281 ; p=0.215$ two-tailed). Supine mean BP [mmHg, $(\mathrm{SEM})]$ prior to drug administration (time $0 \mathrm{~h}$ ) was $87.3(2.7)$ in the placebo group and 86.4 (2.6) in the Reboxetine group. Two hours post-administration (time $+2 \mathrm{~h}$ ), repeat supine mean BP was 84.5 (2.6) in the placebo group and 88.2 (3.4) in the Reboxetine group. A group (placebo, Reboxetine) $\times$ time point $(0 \mathrm{~h},+2 \mathrm{~h})$ $2 \times 2$ repeated measures ANOVA on mean BP revealed a drug $x$ time point interaction at trend $\left(F_{1,10}=3.883, p=0.077\right)$. A post hoc independent $t$-test on the modulation by drug of the difference in 


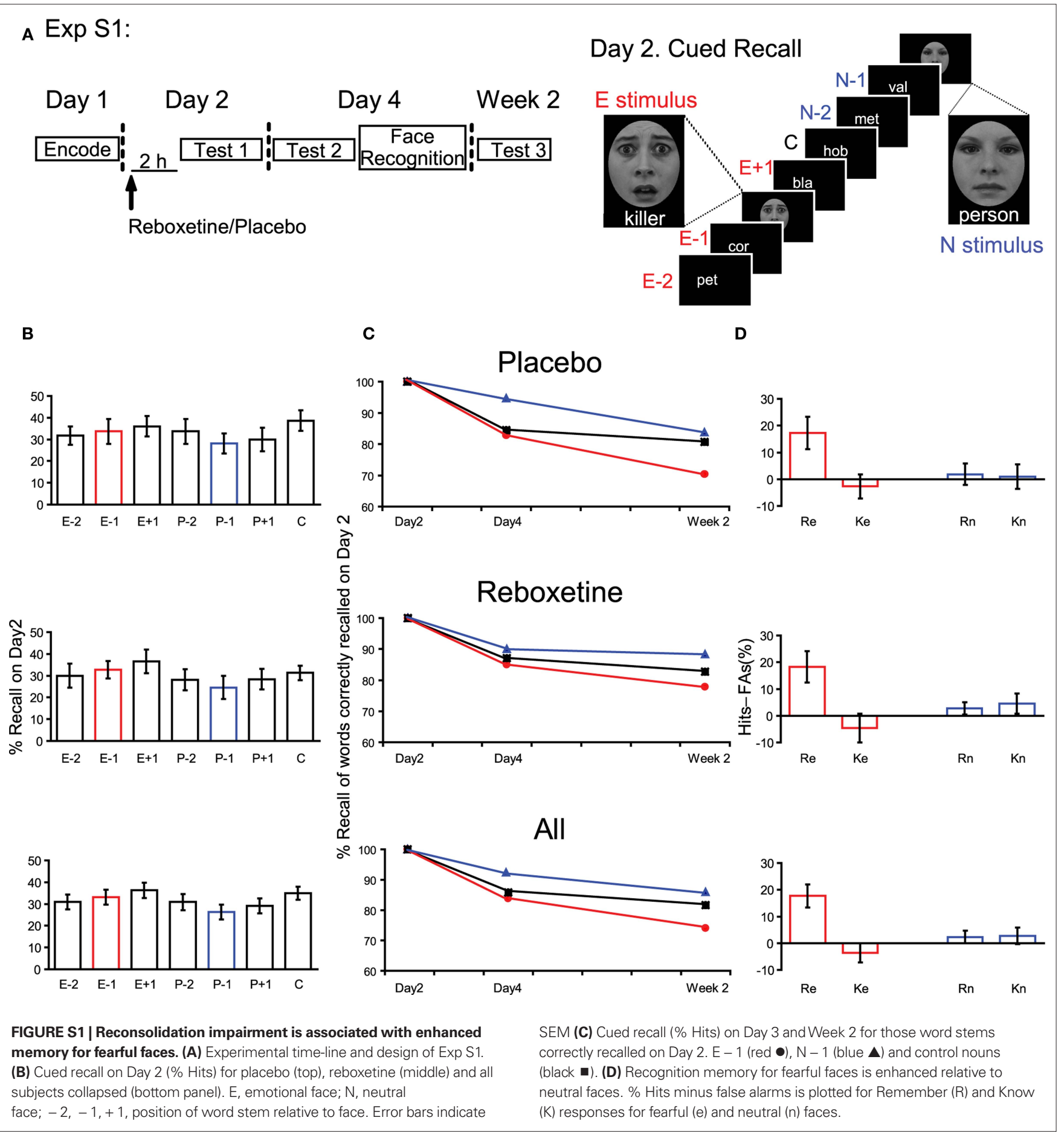

mean $\mathrm{BP}$ at time $0 \mathrm{~h}$ vs. time $+2 \mathrm{~h}$ was significant $(t(20)=2.328$; $p=0.031$ two-tailed). Thus, Reboxetine did not affect memory performance on Day 2, despite evoking a small increase in BP at the time of testing.

Figure S1C demonstrates memory performance on Day 4 and Week 2 for nouns correctly recalled on Day 2. A group (placebo, Reboxetine $) \times$ day $($ Day 4 , Week 2$) \times$ word stem type $($ E, N $) \times$ position $(-2,-1,+1) 2 \times 2 \times 2 \times 3$ ANOVA for \% Hits minus controls failed to reveal any significant main effect or interaction. In view of the lack of significant memory modulation by Reboxetine, we collapsed across the group factor and performed a day (Day 4, Week 2) $\times$ word stem type $(\mathrm{E}-1, \mathrm{~N}-1) 2 \times 2$ ANOVA comparing $\mathrm{E}-1$ and $\mathrm{N}-1 \%$ Hits. This revealed a significant effect of word type $F_{1,20}=5.204, p=0.034$, and no significant main effect of day or word type $x$ day interaction. Restricting this analysis to the placebo group revealed only an effect of word type $F_{1,10}=4.814, p=0.053$. 
Following the cued recall test on Day 4, subjects performed a surprise memory test on faces presented on Day 2. Figure S1D demonstrates recognition accuracy, expressed as \%Hits - False alarms. A group (placebo, Reboxetine) $x$ facial emotion (fearful, neutral $) \times$ recollection $(\mathrm{R}, \mathrm{K}) 2 \times 2 \times 2$ ANOVA revealed a significant main effect of recollection $F_{1,10}=10.038, p=0.010$ and, critically, a facial emotion $x$ recollection interaction $F_{1,10}=7.629$, $p=0.020$. There was no main effect of drug, or drug $\times$ condition interaction.

The critical observation in this experiment is that memory is enhanced for fearful relative to neutral faces. In keeping with previous studies (Dolcos et al., 2005; Sharot and Yonelinas, 2008), this enhancement is expressed as increased recollection (R) accuracy for emotional stimuli, not increased familiarity $(\mathrm{K})$. Thus, in a manner analogous to our previous observations on the effect of emotion on encoding (Strange et al., 2003), we now demonstrate that reconsolidation impairment, induced by fearful face presentation, is

\section{REFERENCES}

Anderson, A. K., Yamaguchi, Y., Grabski, W., and Lacka, D. (2006). Emotional memories are not all created equal: evidence for selective memory enhancement. Learn Mem. 13, 711-718.

Chamberlain, S., Müller, U., Blackwell, A., Robbins, T., and Sahakian, B. (2006). Noradrenergic modulation of working memory and emotional memory in humans. Psychopharmacology 188, 397-407.

Dolcos, F., LaBar, K. S., and Cabeza, R. (2005). Remembering one year later: role of the amygdala and the medial temporal lobe memory system in retrieving emotional memories. Proc. Natl. Acad. Sci. U.S.A. 102, 2626-2631.

Harmer, C. J., Hill, S. A., Taylor, M. J., Cowen, P. J., and Goodwin, G. M. (2003). Toward a neuropsychological theory of antidepressant drug action: increase in positive emotional bias after potentiation of norepinephrine activity. Am. J. Psychiatry 160, 990-992.

Hurlemann, R., Hawellek, B., Matusch, A., Kolsch, H., Wollersen, H., Madea, B.,

associated with enhanced memory for the fearful faces themselves. This supports our suggestion that the reconsolidation impairment we observe is mediated by amygdala-dependent adrenergic activation, evoked by fearful face presentation, which boosts face memory while corrupting a pre-existent memory network reactivated sometime in the preceding $4 \mathrm{~s}$.

As an additional manipulation in this study, we tested for an effect of Reboxetine on reconsolidation impairment induced by emotional stimuli. This was based on a previous observation that Reboxetine augments the emotion-induced retrograde impairment of memory at encoding (Hurlemann et al., 2005). The findings from this study (Hurlemann et al., 2005), however, are in contrast to other reports showing no effect of Reboxetine on memory recall of negative valence stimuli (Papps et al., 2002; Harmer et al., 2003; Chamberlain et al., 2006). The absence of any significant effect of Reboxetine on reconsolidation impairment or face memory is, therefore, in line with these latter studies.

Vogeley, K., Maier, W., and Dolan, R. J. (2005). Noradrenergic modulation of emotion-induced forgetting and remembering. J. Neurosci. 25, 6343-6349.

Papps, B., Shajahan, P., Ebmeier, K, and O'Carroll, R. (2002). The effects of noradrenergic re-uptake inhibition on memory encoding in man. Psychopharmacology 159, 311-318.

Sergerie, K., Lepage, M., and Armony, J. L. (2005). A face to remember: emotional expression modulates prefrontal activity during memory formation. Neuroimage 24, 580-585.
Sharot, T., Yonelinas, A. P. (2008) Differential time-dependent effects of emotion on recollective experience and memory for contextual information. Cognition 106, 538-547.

Strange, B. A., Hurlemann, R., and Dolan, R. J. (2003). An emotion-induced retrograde amnesia in humans is amygdala- and $\beta$-adrenergic-dependent. Proc. Natl. Acad. Sci. U.S.A. 100, 13626-13631.

Tulving, E. (1985). Memory and consciousness. Can. Psychol. 26, 1-12. 